\title{
Multiple Morphological Variations in a Human Mandible
}

\author{
Múltiples Variaciones Morfológicas en una Mandíbula Humana
}

\author{
Huseyin Avni Balcioglu*; Taha Emre Kose ${ }^{* * *}$ \& Yigit Uyanikgil ${ }^{* * *}$
}

BALCIOGLU, H. A.; KOSE, T. E. \& UYANIKGIL, Y. Multiple morphological variations in a human mandible. Int. J. Morphol., 33(3):10231026, 2015.

SUMMARY: Bilateral mylohyoid bridging, hyperplasia of the coronoid process and bifid condylar process were detected in a human mandible. It is of great interest that such rare morphological anomalies can occur in the same mandible. Since sound understanding of the anatomical variations of the mandible, in conjunction with a careful pre-operative review of radiographs, are essential in the safe and complete performance of surgical and prosthetic rehabilitation, the authors of the present report believe that this case may add to the existing literature.

KEY WORDS: Mandible; Mylohyoid bridge; Coronoid hyperplasia; Bifid mandibular condyle.

\section{INTRODUCTION}

Vital anatomical structures should be localized with an utmost care during the presurgical planning in maxillofacial surgery. In order to achieve better results in surgical procedures and to avoid complications during surgery, it is essential to establish the location and course of anatomical structures, particularly the variations, in the region. The probability of the existence of an anatomical variation, which may be congenital, developmental or acquired, may result in neurovascular complications during procedures such as regional anesthesia, implant placement and surgical correction of jaw deformities. Besides, knowledge of variational anatomy provides superiority in radiologic interpretation and prosthetic rehabilitation.

\section{CASE REPORT}

Multiple anatomical variations were observed in a dry human mandible in the Osteology Lab of the Anatomy Department at Istanbul University Faculty of Dentistry:

1-Bilateral mylohyoid bridging.

2- Hyperplasia of the right coronoid process

3- Bifid condylar process on the right side

In order to evaluate the mylohyoid canal, CT scans were obtained with $1 \mathrm{~mm}$ slices in the coronal and sagittal plane using a cone beam computed tomography (NewTom 3G, Japan) (Fig. 1). The photographic images of the mandible were acquired using a digital camera (Figs. 2 and 3). Panoramic radiography obtained with Kodak 8000 digital panoramic radiography device (Fig. 4).

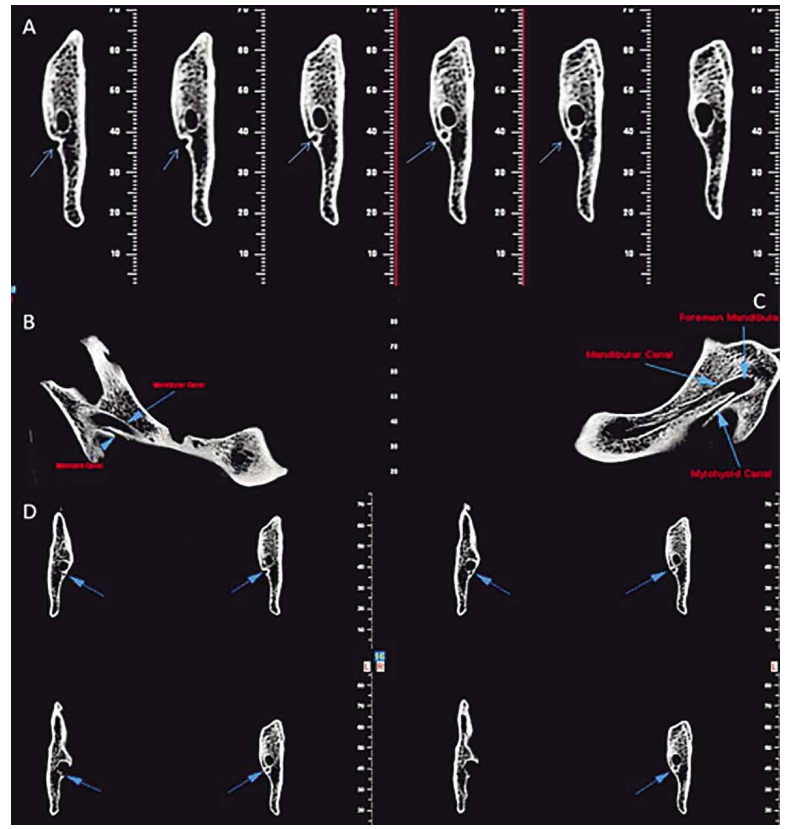

Fig. 1. A) Cross-sectional scans of the mylohyoid canal at the right side; B) Sagittal view of the right mandibular ramus, arrows: mandibular canal and mylohyoid canal; C) Sagittal view of the left mandibular ramus, arrows: mandibular foramen, mandibular canal and mylohyoid canal; D) Coronal sections of the right and left mylohyoid canal.

Istanbul University, Faculty of Dentistry, Department of Anatomy, Istanbul, Turkey.

** Istanbul University, Faculty of Dentistry, Department of Oral and Maxillofacial Radiology, Istanbul, Turkey.

${ }^{* * *}$ Ege University, Faculty of Medicine Department of Embryology, Izmir, Turkey. 


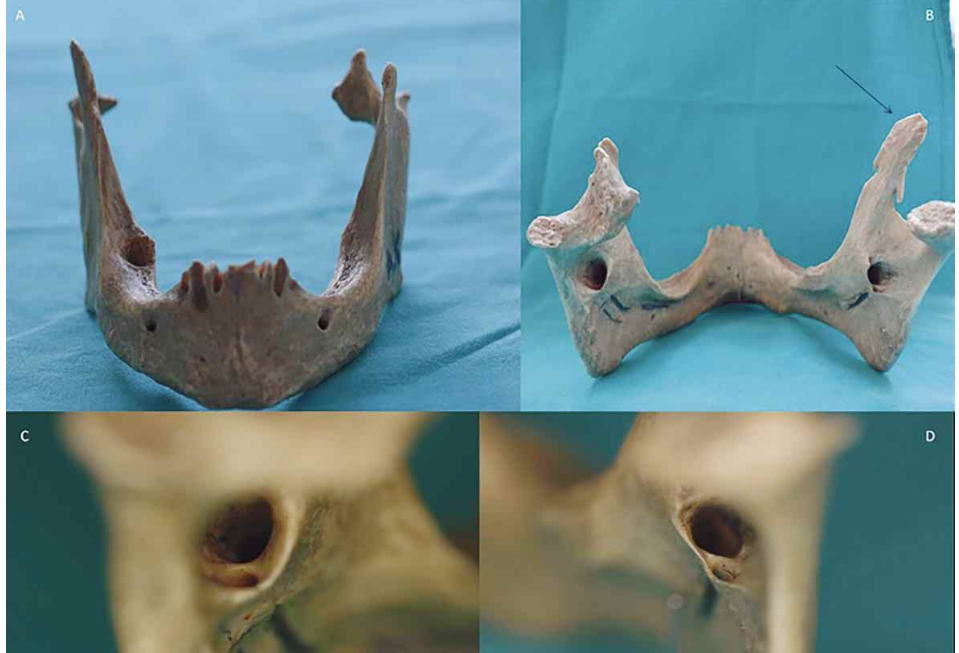

Fig. 2. A) Anterior view of the mandible; B) Lingual view of the mandible, HCP: Hyperplastic coronoid process; C) Inlet of the mylohyoid canal inferior to the left mandibular foramen; D) Inlet of the mylohyoid canal inferior to the right mandibular foramen.

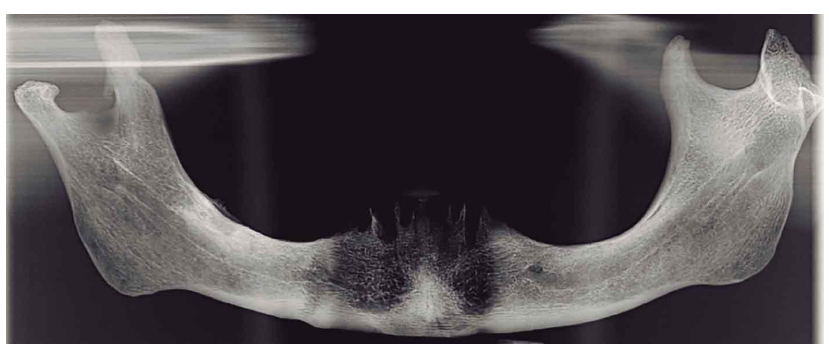

Fig. 4. Panoramic radiography of the case.

\section{DISCUSSION}

The mylohyoid nerve is a branch of the inferior alveolar nerve (IAN); it courses anteroinferiorly in a groove on the medial aspect of the mandibular ramus to supply the mylohyoid muscle and the anterior belly of the digastric muscle. As it runs forward on the medial surface of the mandible, it travels in a groove that may be converted into a canal by a bony bridge (Bennett \& Townsend, 2001). This canal by a bridge of bone, as a morphological variation, has been called as mylohyoid bridging, arcus mhyloideus, ponticulus mylohyoideus or canalis mylohyoideus (Hanihara \& Ishida, 2001).

Mylohyoid bridging (MB) may be derived from Meckel cartilage. It was asserted to have a genetic trait and be a useful genetic marker for population related studies (Kilic et al., 2010; Ossenberg, 1974; Jidoi et al., 2000). Even though the affinity for certain population groups was falsified (Lundy, 1980), bony variations such as mylohyoid bridging may be reliable markers (Sawyer, 1990).

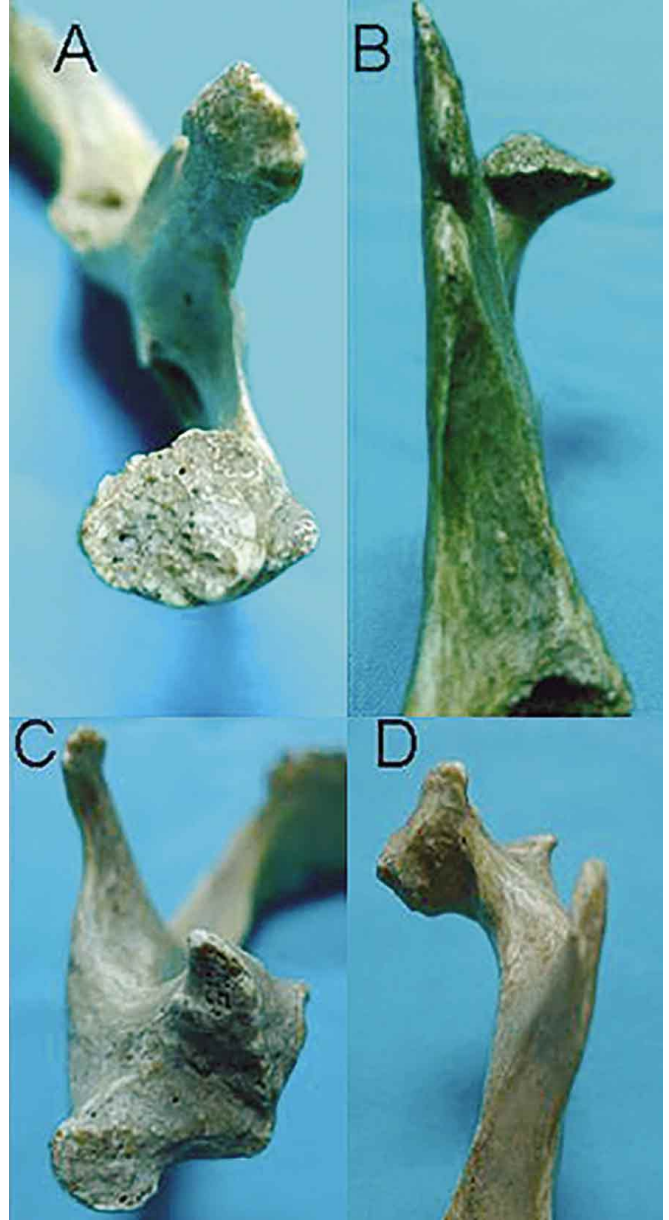

Fig. 3. A) Right condyle view from upper posterior; B) Right condyle view from anterior; C) Left condyle view from upper posterior, D) Left condyle view from anterior.

The frequency of the MB differs according to the various nations. Ishida and Hanihara stated that the prevalence of the MB in males was higher in Arctic, Melanisian and Ainu samples while the prevalence in women was higher in Middle Asia and UK (Hanihara \& Ishida). Various studies in different countries have reported that the prevalence of MB ranges between 0.47-32.2\% (Narayana et al., 2007). Studies performed in Anatolian samples showed an incidence ranging from $6.07 \%$ to $30 \%$ (Eroglu, 2011). However, it is almost never found in subjects under 11 years of age (Ossenberg).

Mylohyoid nerve is thought to have a role in the sensory innervation of the jaw and innervation of the posterior mandibular teeth (Potu et al., 2010). In case of IAN block failure, mylohyoid nerve block is required. As Ossenberg claimed that membranous precursor of the bony bridge may prevent anesthetic solution to reach the groove 
and thus block the mylohyoid nerve. Besides, it is suggested that the existence of a MB may result in compression of mylohyoid nerve and vessels (Narayana et al.).

A deep mylohyoid groove, with MB or not, or a lingual vascular canal on panoramic radiographies (PR) may be confused with a bifid mandibular canal. In a study of 2 012 PRs, the number of the identified double canals was found as seven on PRs, but corrected as two cases following a CT examination (Rouas et al., 2007). Consequently, PR is not an ideal method for the identification of a canal or a groove since false negatives/positives or misinterpretations may lead to complications such as anaesthesia, paraesthesia, hemorrhage, etc.

Hyperplasia of the coronoid process of the mandible, first defined by Von Langenbeck in 1853 (Zhong et al., 2009), is a rare developmental anomaly that may lead to limitation of mandibular movement (Neville et al., 2009). The exact etiology of coronoid hyperplasia still remains unknown, however it may be related to trauma, genetics, endocrine abnormalities, temporomandibular joint disorders or hyperactivity of the temporal muscles (Zhong et al.). The prevalence of coronoid hyperplasia is reported to be $5 \%$ in a group of patients with limited mouth opening (Rouas et al.). Bilateral cases are five times more common than unilaterals, and more frequent in males (Fernandez Ferro et al., 2008). Unilateral cases can result from a true tumor, such as an osteoma or osteochondroma, therefore the cases should be distinguished from pure coronoid hyperplasia (Neville et al.). The Levandoski panoramic radiograph analysis has been proven to be useful in evaluating hyperplasia of the coronoid process (Zhong et al.). On the other hand, even though PR as a simple, cheap and relatively reliable method should be the first preference,superimposition of the coronoid process over the maxillary tuberosity and the laminae of the pterygoid process keeps it from being the golden standard. Therefore CT or 3D CT scans should be obtained prior to surgery.

Bifid mandibular condyle (BMC) is a rare morphological anomaly, which is differently characterized from condylar hyperplasia. The etiological factors and pathogenesis of this morphological and clinical case are not yet well understood. Developmental, traumatic, genetic, endocrinal, teratogenic and vascular factors have been thought as possible causes (Sala-Pérez et al., 2010; Menezes et al., 2008). No sexual dimorphism has been shown in the previous studies. Bilateral involvement is only one eight of the unilateral cases (Gulati et al., 2009).

Condylar growth in posterosuperior direction leads to an increase in the vertical length of the mandibular ramus. The newly formed ramus remodels in a process characterized with periosteal resorption and endosteal bone deposition in much of the mandibular neck and ascending ramus of the mandible (Smartt et al., 2005). A corruption or a failure in the process may result in abnormal coronoid and condylar processes.

The morphology of the BMC may vary from grooving to discrete condylar heads and the orientation may be mediolateral or anteroposterior. The bifidity of the condylar heads may be seen as a grooving or discrete condyles localized in anteroposterior or mediolateral direction (SalaPérez et al.). In the present case, two distinct condylar heads are oriented in mediolateral direction.

Clinically, BMC is mostly asymptomatic and is usually detected coincidentally through panoramic radiographs, however, detection of morphological or neoplastic changes in the condylar shape may be misleading, as Crow et al. (2005), suggested. In cases of clinical symptoms, PR is not a reliable and unbiased method for detection of tumors, so that further imaging methods should be preferred, even though malignant tumors of the temporomandibular joint are rare.

Intimate knowledge and understanding of the anatomical variations of the mandible, in conjunction with a careful pre-operative assessment of CT scans, are paramount in the safe and complete performance of surgical and prosthetic rehabilitation.

\section{ACKNOWLEDGEMENTS}

The authors would like to thank Dr. Sinan Horasan for his excellent technical assistance.

BALCIOGLU, H. A.; KOSE, T. E. \& UYANIKGIL, Y. Múltiples variaciones morfológicas en una mandíbula humana. Int. $\boldsymbol{J}$. Morphol., 33(3):1023-1026, 2015.

RESUMEN: En una mandíbula humana se detectó puente milohioideo bilateral, hiperplasia del proceso coronoides y el proceso condilar bífido. Es de interés que se puedan producir dichas anomalías morfológicas en la misma mandíbula. Es esencial un conocimiento sólido de las variaciones anatómicas de la mandíbula, en conjunción con una revisión preoperatoria cuidadosa de las radiografías, en el desempeño seguro y completo de la rehabilitación quirúrgica y protésica. Los autores del presente estudio estiman que este caso puede aportar información a la literatura existente.

PALABRAS CLAVE: Mandíbula; Puente milohioideo; Hiperplasia coronoides; Cóndilo. mandibular bífido. 


\section{REFERENCES}

Bennett, S. \& Townsend, G. Distribution of the mylohyoid nerve: anatomical variability and clinical implications. Aust Endod J., 27(3):109-11, 2001.

Crow, H. C.; Parks, E.; Campbell, J. H.; Stucki, D. S. \& Daggy, J. The utility of panoramic radiography in temporomandibular joint assessment. Dentomaxillofac Radiol., 34(2):91-5, 2005.

Eroglu, S. The incidence of mylohyoid bridging in prehistoric and historic Anatolian populations. Eurasian J. Anthropol., 2(1):1526, 2011.

Fernández Ferro, M.; Fernández Sanromán, J.; Sandoval Gutierrez, J.; Costas López, A.; López de Sánchez, A. \& Etayo Pérez, A. Treatment of bilateral hyperplasia of the coronoid process of the mandible. Presentation of a case and review of the literature. Med. Oral Patol. Oral Cir. Bucal, 13(9):E595-8, 2008.

Gulati, A.; Virmani, V.; Ramanathan, S.; Verma, L. \& Khandelwal, N. Bifid mandibular condyle with temporomandibular joint ankylosis: report of two cases and review of literature. Skeletal Radiol., 38(10):1023-5, 2009.

Hanihara, T. \& Ishida, H. Frequency variations of discrete cranial traits in major human populations. III. Hyperostotic variations. J. Anat., 199(Pt. 3):251-72, 2001.

Jidoi, K.; Nara, T. \& Dodo, Y. Bony bridging of the mylohyoid groove of the human mandible. Anthropol Sci., 108:345-70, 2000.

Kılıç, C.; Kamburoglu, K. \& Özen, T. A mylohyoid nerve traveling within the mandibular canal: A case report. Trakya Univ. Tip. Fak. Derg., 27(3):297-9, 2010.

Lundy, J. K. The mylohyoid bridge in the Khoisan of Southern Africa and its unsuitability as a mongoloid genetic marker. Am. J. Phys. Anthropol., 53(1):43-8, 1980.

Menezes, A. V.; de Moraes Ramos, F. M.; de Vasconcelos-Filho, J. O.; Kurita, L. M.; de Almeida, S. M. \& Haiter-Neto, F. The prevalence of bifid mandibular condyle detected in a Brazilian population. Dentomaxillofac Radiol., 37(4):220-3, 2008.

Narayana, K.; Narayan, P.; Ashwin, K. \& Prabhu, L. V. Incidence, types and clinical implications of a non-metrical variant-mylohyoid bridging in human mandibles. Folia Morphol. (Warsz.), 66(1):20-4, 2007.

Neville, B. W.; Douglas, D. D.; Allen, C. M. \& Bouquot, J. Oral and Maxillofacial Pathology. 3th ed. St. Louis, Saunders Elsevier, 2009.

Ossenberg, N. S. The mylohyoid bridge: an anomalous derivative of Meckel's cartilage. J. Dent. Res., 53(1):77-82, 1974.
Potu, B. K.; D'Silva, S. S.; Thejodhar, P. \& Jattanna, N. C. An unusual communication between the mylohyoid and lingual nerves in man: its significance in lingual nerve injury. Indian J. Dent. Res., 21(1):141-2, 2010.

Rouas, P.; Nancy, J. \& Bar, D. Identification of double mandibular canals: literature review and three case reports with CT scans and cone beam CT. Dentomaxillofac. Radiol., 36(1):34-8, 2007.

Sala-Pérez, S.; Vázquez-Delgado, E.; Rodríguez-Baeza, A. \& GayEscoda, C. Bifid mandibular condyle: a disorder in its own right? J. Am. Dent. Assoc., 141(9):1076-85, 2010

Sawyer, D. R.; Gianfortune, V.; Kiely, M. L. \& Allison, M. J. Mylohyoid and jugular foramen bridging in pre-Columbian Chileans. Am. J. Phys. Anthropol., 82(2):179-81, 1990.

Smartt, J. M. Jr.; Low, D. W. \& Bartlett, S. P. The pediatric mandible: I. A primer on growth and development. Plast. Reconstr. Surg., 116(1):14e-23e, 2005.

Zhong, S. C.; Xu, Z. J.; Zhang, Z. G.; Zheng, Y. H.; Li, T. X. \& Su, K. Bilateral coronoid hyperplasia (Jacob disease on right and elongation on left): report of a case and literature review. Oral Surg. Oral Med. Oral Pathol. Oral Radiol. Endod., 107(3):e647, 2009.

\section{Correspondence to: \\ Doc. Dr. Hüseyin Avni Balcıoglu \\ Istanbul Üniversitesi DisHekimligi Fakültesi \\ Çapa, Istanbul \\ TURKEY}

Email: habalci@istanbul.edu.tr

Received: 04-05-2015

Accepted: 28-05-2015 